\title{
A Measurement and Power Line Communication System Design for Renewable Smart Grids
}

\author{
E. Kabalci ${ }^{1}$, Y. Kabalci ${ }^{2}$ \\ ${ }^{1}$ Department of Electrical and Electronics Eng., Faculty of Engineering and Architecture, Nevsehir University, \\ 50300 Nevsehir, Turkey, kabalci@nevsehir.edu.tr \\ ${ }^{2}$ Department of Electronics and Automation, Nigde Vocational College of Technical Sciences, Nigde University, \\ 51200 Nigde, Turkey, yasinkabalci@nigde.edu.tr
}

\begin{abstract}
The data communication over the electric power lines can be managed easily and economically since the grid connections are already spread around all over the world. This paper investigates the applicability of Power Line Communication (PLC) in an energy generation system that is based on photovoltaic (PV) panels with the modeling study in Matlab/Simulink. The Simulink model covers the designed PV panels, boost converter with Perturb and Observe (P\&O) control algorithm, full bridge inverter, and the binary phase shift keying (BPSK) modem that is utilized to transfer the measured data over the power lines. This study proposes a novel method to use the electrical power lines not only for carrying the line voltage but also to transmit the measurements of the renewable energy generation plants. Hence, it is aimed at minimizing the additional monitoring costs such as SCADA, Ethernet-based or GSM based systems by using the proposed technique. Although this study is performed with solar power plants, the proposed model can be applied to other renewable generation systems. Consequently, the usage of the proposed technique instead of SCADA or Ethernet-based systems eliminates additional monitoring costs.
\end{abstract}

Keywords: Renewable energy, photovoltaic panels, power line communication, BPSK, remote monitoring.

\section{INTRODUCTION}

$\mathrm{T}$ HE DISTRIBUTED power generation systems (DPGS) based on renewable energy sources such as photovoltaic (PV) cells, wind turbines, and micro-turbines have been experiencing a rapid development since the last decade. The distributed generation (DG) allows installing relatively small-scale power generators at the medium and low-voltage distribution levels of the power system [1-3]. Generating energy by using the PVs is also becoming an interesting area among other renewable energy sources. The solar energy sources provide the advantages of not causing pollution and having low maintenance cost. Furthermore, they do not produce any noise since there is not any moving part utilized in the entire system $[4,5]$.

Generally, PVs are considered as an expensive method of generating electricity. However, stand-alone PV applications are the most economic solutions to provide the required power service. The single-phase or three-phase pulse-width modulation (PWM) voltage-source inverters (VSIs) are often used in grid-connected systems to interface the renewable energy source to the utility grid, and the current control of the grid-connected inverters plays a predominant role in feeding the grid with high-quality power. For gridconnected systems, the cost is further reduced due to the elimination of battery requirements, which is the second largest contributor to the cost of a PV system. The cost of the grid-connected system can also be minimized by decreasing the number of power conversion stages and the number of components involved in each stage $[6,7]$.

Up to now, various energy-monitoring techniques have been proposed for both conventional and renewable energy sources in the literature. These monitoring systems are generally based on Supervisory Control and Data Acquisition (SCADA) [8-10], Ethernet-based [11, 12] or GSM based systems $[13,15]$. However, the utilization of these methods requires additional costs for the energy systems.

The study given in this paper focuses on modeling a PV panel and maximum power point tracker (MPPT) control in the energy conversion system design. The modeled PV panel is able to adjust the parameters such as open circuit voltage $\left(\mathrm{V}_{\mathrm{oc}}\right)$, maximum power voltage $\left(\mathrm{V}_{\mathrm{pm}}\right)$, short circuit current $\left(\mathrm{I}_{\mathrm{sc}}\right)$, and maximum power current $\left(\mathrm{I}_{\mathrm{pm}}\right)$. The output of the boost converter is supplied to a VSI in order to generate a three-phase conversion system with a power line communication (PLC) model. The PLC part of the system is constituted referring to binary phase-shift keying (BPSK) modulation technique that is a digital modulation technique. Since the BPSK modulation scheme is the least affected one by noise among others, it has been selected to transmit and receive the data on the proposed monitoring system.

In this study, a novel technique is proposed where the electrical power lines are not only used to carry the generated voltage but also used to transmit the measured data of the solar plants. Hence, it is aimed to minimize the additional monitoring costs mentioned above by using the proposed technique instead of the SCADA, Ethernet-based or GSM based systems.

The remainder of this paper is structured as follows: Section 2 describes the architecture of the energy conversion model while the designed PLC model is presented in Section 3 , the measurement and analysis results of the proposed system are given in Section 4, and finally, conclusions are drawn in Section 5. 


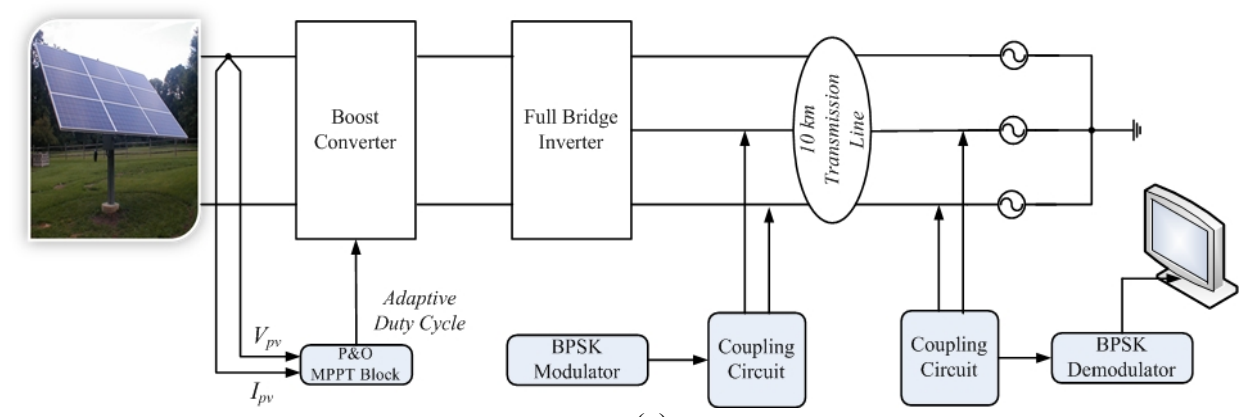

(a)

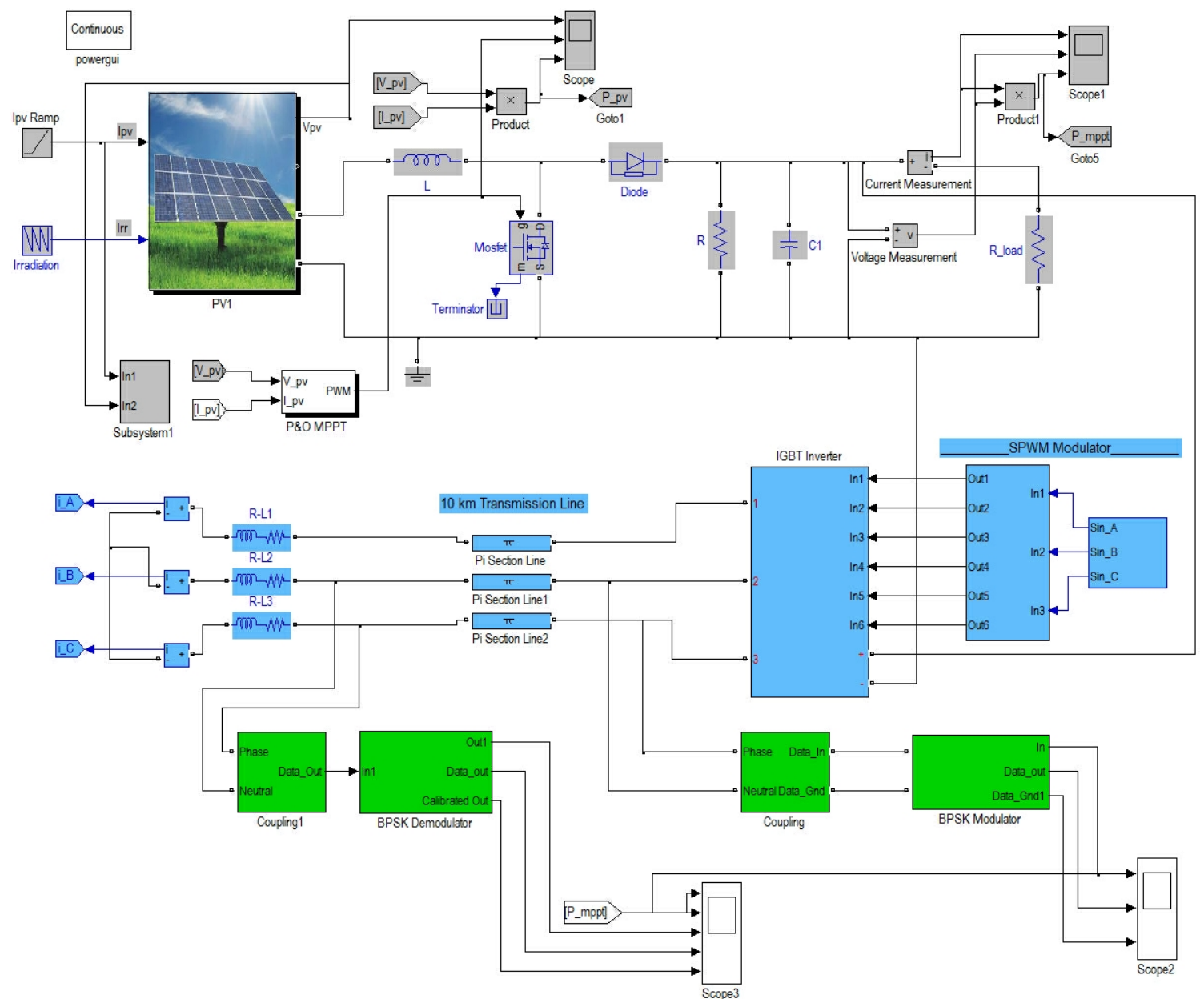

(b)

Fig.1. Designed PLC system with BPSK modem for PV panels: a) Block diagram of proposed system, b) Matlab/Simulink model with $10 \mathrm{~km}$ transmission line.

\section{DESIGN OF THE ENERGY CONVERSION MODEL}

The PV system designed in Matlab/Simulink environment is shown in Fig.1. The number of serially connected PV panels can also be fixed by using the PV model in the modeled system. The physical parameters of the PV panel are set according to NE-170UC1 solar panel by Sharp, which has maximum power output about $170 \mathrm{~W}$ [16]. An MPPT block that utilizes the actual voltage and current values of the PV panel stabilizes the output value of the PV panel. The MPPT algorithm is based on Perturb and Observe $(\mathrm{P} \& \mathrm{O})$ control strategy in order to commutate the boost converter at the maximum power point. The Mosfet switches used in the boost converter are controlled at $20 \mathrm{kHz}$ switching frequency. The output of the boost converter is fed to a three-phase inverter in order to generate three-phase AC voltages. The control algorithm of the inverter is based on sinusoidal pulse width modulation (SPWM) scheme that is a highly efficient algorithm in terms of eliminating total harmonic distortion (THD) ratios among other control schemes such as Third-Harmonic Injection PWM (THI-PWM) and Space Vector PWM (SVM) [17, $18]$. 


\section{DESIGN OF THE PLC MODEL}

The BPSK modulator is connected to the output of the VSI in order to utilize the power line as a transmission medium. The modulating data in this study are selected as the output power information of the PV panels. The modulator output is coupled with line trapper circuit models that are designed in Simulink. The length of the transmission path is set to 10 $\mathrm{km}$ and the modulated data are injected to line voltage by using two of three phases. The demodulator part of the BPSK modem, which is located at the end of the line, is also coupled with a trapper similar to the modulator side trapper. The attenuated line voltage with the BPSK modulated data are supplied to the demodulator and they are filtered at the output of the demodulator in order to eliminate harmonic contents. The transmission line parameters that are used in this study are shown in Table 1.

Table 1. Physical properties of the transmission line.

\begin{tabular}{|c|c|}
\hline Unit & Value \\
\hline Resistance & $0.2568 \Omega / \mathrm{km}$ \\
\hline Inductance & $4 \times 10^{-7} \mathrm{H} / \mathrm{km}$ \\
\hline Capacitance & $8.6 \times 10^{-9} \mathrm{~F} / \mathrm{km}$ \\
\hline Length & $10 \mathrm{~km}$ \\
\hline
\end{tabular}

The resistance, inductance, and capacitance parameters are defined for per $\mathrm{km}$ in the PI section line model. The coupling circuit contains a 1:1 isolation transformer that is connected in parallel to an R-L-C network as illustrated in Fig. 2 .

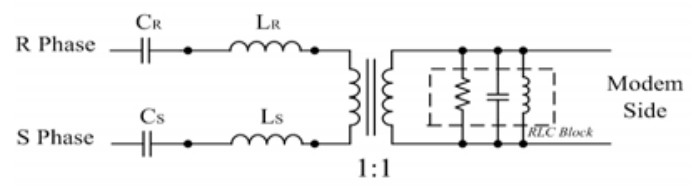

Fig.2. The coupling circuit model between grid and modem.

The BPSK signal $s(t)$ is represented by

$$
s(t)=A_{c} \cos \left[\omega_{c}+D_{p} m(t)\right]
$$

where $A_{c}$ is the carrier amplitude, $\omega_{c}$ is the carrier frequency in radians, $D_{p}$ is the phase deviation, and $m(t)$ is a polar baseband data signal. If it is assumed that $m(t)$ has peak values of \pm 1 and has a shape in rectangular pulse, then the equation can show that the BPSK is also a form of AM-type signaling. It is obtained by expanding (1),

$$
\begin{aligned}
s(t)= & A_{c}\left[\cos \left(D_{p} m(t)\right) \cos \left(\omega_{c} t\right)\right] \\
& -A_{c}\left[\sin \left(D_{p} m(t)\right) \sin \left(\omega_{c} t\right)\right]
\end{aligned}
$$

Recalling that $m(t)$ has values of \pm 1 and that $\cos (x)$ and $\sin (x)$ are even and odd functions of $x$, the representation of the BPSK signal reduces to

$$
s(t)=\underbrace{\left(A_{c} \cos D_{p}\right) \cos \omega_{c} t}_{\text {pilot carrier term }}-\underbrace{\left(A_{c} \sin D_{p}\right) m(t) \sin \omega_{c} t}_{\text {data term }}
$$

The principle schematic diagrams of the BPSK modulator and demodulator are depicted in Fig.3. The digital data signal is multiplied to cosine function of carrier so as to generate BPSK modulated signal as shown in Fig.3(a). The demodulator is based on timing recovery function as illustrated in Fig.3(b). The CR parameter defines the carrier while STR is Symbol Timing Recovery that enables sampling in each period of $T_{0}$ interval. Depending on the logical condition of the digital input, the carrier is transferred to the output, either in phase or at $180^{\circ}$ outside of phase, with the reference carrier oscillator [19], [20].

\section{MEASUREMENT AND ANALYSIS RESULTS OF THE PROPOSED SYSTEM}

The simulation diagram of the proposed PLC system with BPSK modem was shown in Fig.1. The PLC process is analyzed in two ways - one of them is energy analysis and the other one is communication analysis. Fig.4. illustrates line current harmonic $\left(\mathrm{THD}_{\mathrm{i}}\right)$ analyses of the inverter for various conditions. The $\mathrm{THD}_{\mathrm{i}}$ analysis up to $50^{\text {th }}$ harmonic order is shown in Fig.4. and it is measured at $3.66 \%$ at the end of transmission, while the line was carrying the BPSK modulated signal. The $3^{\text {rd }}$ harmonic is measured at $1.31 \%$ while the $5^{\text {th }}$ is $1.02 \%$, the $7^{\text {th }}$ is $1.13 \%$, and the $9^{\text {th }}$ is $0.36 \%$. The THD spectrum analyzed in Fig. 4 . also shows that the side band harmonics are mitigated due to the used SPWM control method. When the THD analyses are replying by increasing the harmonic spectrum up to $5000 \mathrm{~Hz}$ and $10000 \mathrm{~Hz}$, respectively, the measured $\mathrm{THD}_{\mathrm{i}}$ ratios do not change eventually. The most effective side band harmonics are observed around $90^{\text {th }}$ order. The $86^{\text {th }}, 90^{\text {th }}$, $92^{\text {nd }}$, and $98^{\text {th }}$ harmonics are increasing according to other harmonics with $0.16 \%, 0.23 \%, 0.25 \%$, and $1.00 \%$ values. The symmetric sides of these side band harmonics are measured at $114^{\text {th }}, 110^{\text {th }}, 108^{\text {th }}$, and $102^{\text {nd }}$ with the respective values of $0.13 \%, 0.20 \%, 0.24 \%$, and $0.94 \%$.

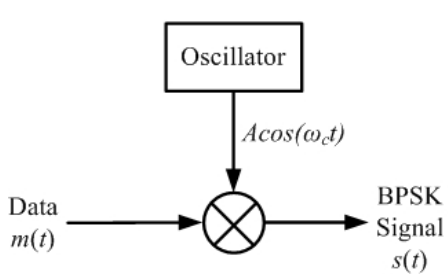

(a)

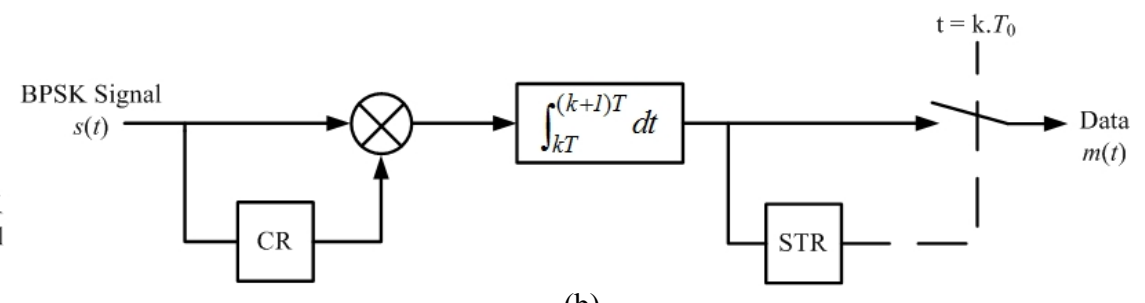

(b)

Fig.3. BPSK modem structures: a) Modulator structure, b) Demodulator structure. 


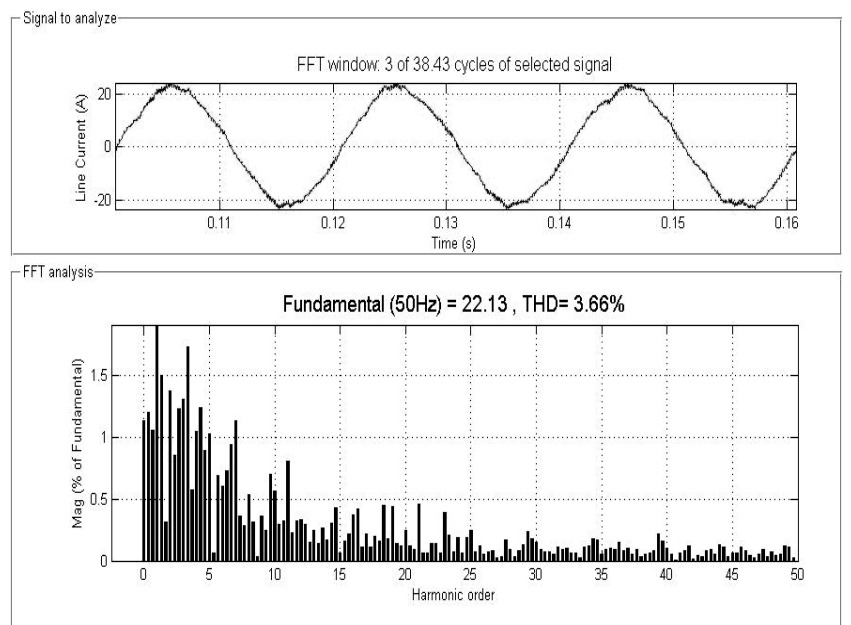

Fig.4. Current THD analyses of the PV based inverter up to $50^{\text {th }}$ order

The side band harmonics around $5000 \mathrm{~Hz}$ are caused by the BPSK modulated signal injected to the power line over the coupling circuitry. The performed analyses show that the PLC signal that is injected into the transmission line does not cause any undesired effect on the generated line voltage.
The communication analysis and PLC properties are examined to determine the most proper operation conditions using Fig.5(a). and Fig.5(b). The BPSK modulator and demodulator signal carrying the power of the PV panel is shown in Fig.5. The frequency of the BPSK carrier is set to $8 \mathrm{kHz}$. The first curves depict the output power of the PV as measured data signal, while the second curves are the quantized data signals of the BPSK modulator. The third curves show the demodulated data signals at the output of the BPSK demodulator. The filtered and calibrated data at the end of the transmission line are seen in the fourth and fifth curves, respectively. The filtering effect is easily realized by comparing the fourth and fifth curves in Fig.5(a). and Fig.5(b). The filtering band is adjusted between $250 \mathrm{~Hz}$, which is defined as fine filtering, and $4 \mathrm{kHz}$ that is the upper limit of low-pass filter. The last curve of Fig.5(b). is obtained at the cut-off limits of the low-pass filter used at the output of the demodulator and provides the most adequate signals. The measured maximum ripple was around $100 \mathrm{~W}$ in the $250 \mathrm{~Hz}$ filtered case, as it was over $500 \mathrm{~W}$ in the $4 \mathrm{kHz}$ filtered condition.

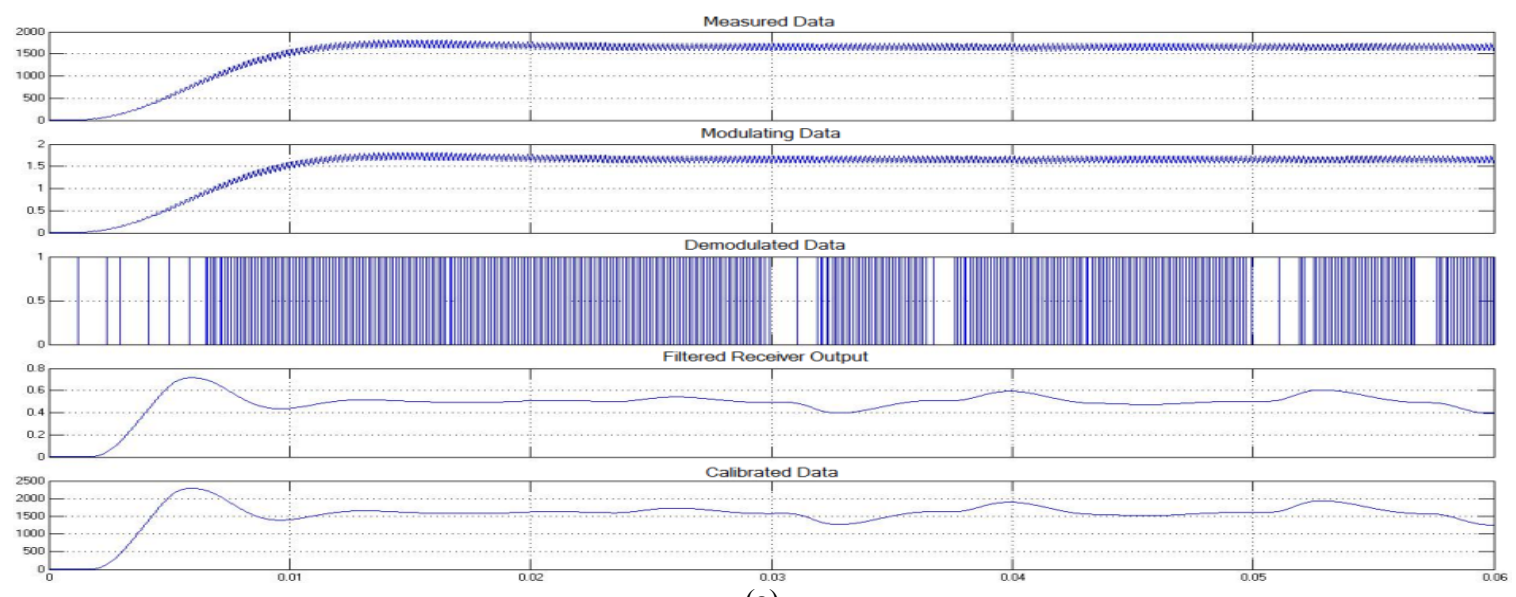

(a)
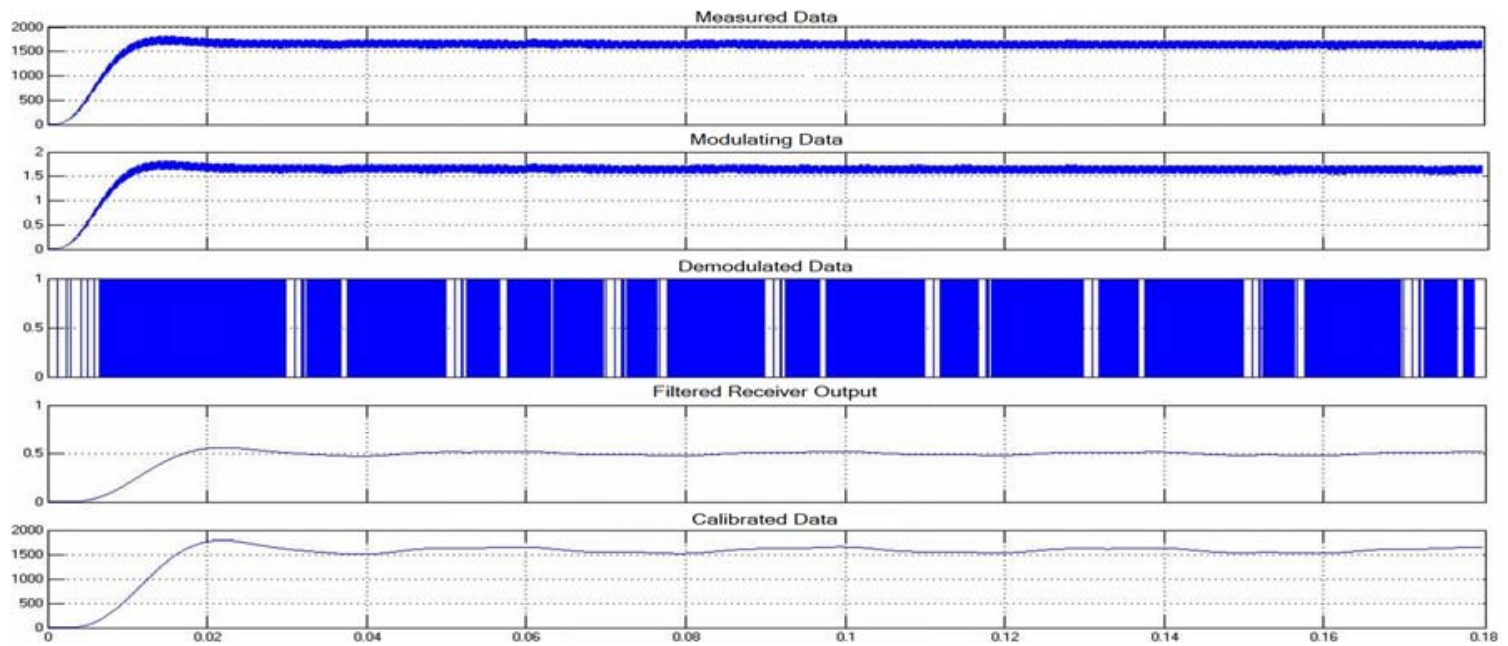

(b)

Fig.5. BPSK modulator and demodulator analyses: a) Coarse filtering, b) Fine filtering. 


\section{CONCLUSION}

The proposed system focuses on transmitting the measured data of the modeled PV-based-DG system by using the power line commutation technique developed with BPSK modulation in this study. The modeled system has also been improved to enable to simulate serial connections of panels in the model. The boost converter is controlled with an MPPT algorithm based on the P\&O control scheme. The obtained DC voltage is converted to three-phase AC voltages utilizing an SPWM controlled full-bridge inverter.

The proposed PLC part of the study is based on coupling the modulation and demodulation system through the AC power line. The modulated signals that contain the measured data of the PV panels are transmitted over the electrical power lines and the designed demodulator at the end of the transmission line receives them. The THD analysis performed in the fourth section verifies that there is not any distortional effect seen in the line voltage although the modulated data are embedded to the grid. Moreover, the THD values of the entire system are also measured in the reasonable ranges according to standards about THD values such as IEEE-519-1992 and IEC-61000. The simulation results confirm that the proposed system eliminates the installation costs of a monitoring system, owing to the applied technique, that is required in the SCADA or in any Ethernet-based systems.

\section{REFERENCES}

[1] Singh, G.K. (2008). Modelling and experimental analysis of a self-excited six-phase induction generator for stand-alone renewable energy generation. Renewable Energy, 33 (7), 1605-1621.

[2] Ansari, M.F., Chatterji, S., Iqbal, A. (2010). Automatic maximum power point tracker for solar PV modules using dSPACE software. International Journal of Sustainable Energy, 29 (3), 151-163.

[3] Alvarado, U., Juanicorena, A., Adin, I., Sedano, B., Gutiérrez, I., de Nó, J. (2012). Energy harvesting technologies for low-power electronics. Transactions on Emerging Telecommunications Technologies, 23 (8), 728-741.

[4] Liu, F., Duan, S., Liu, B., Kang, Y. (2008). A variable step size INC MPPT method for PV systems. IEEE Transactions on Industrial Electronics, 55 (7), 26222628.

[5] Kwon, J.M., Kwon, B.H., Nam, K.H. (2008). Threephase photovoltaic system with three-level boosting MPPT control. IEEE Transactions on Power Electronics, 23 (5), 2319-2327.

[6] Kabalci, E., Kabalci, Y. (2010). BPSK modem based power line communication system for observing photovoltaic panels. In 2nd International Conference on Nuclear and Renewable Energy Resources (NURER 2010), 4-7 July 2010. Ankara, Turkey, 284289.

[7] Kim, I.S., Kim, M.B., Youn, M.J. (2006). New maximum power point tracker using sliding-mode observer for estimation of solar array current in the grid-connected photovoltaic system. IEEE Transactions on Industrial Electronics, 53 (4), 1027 1035 .
[8] Patel, M., Cole, G.R., Pryor, T.L., Wilmot, N.A. (2004). Development of a novel SCADA system for laboratory testing. ISA Transactions, 43 (3), 477-490.

[9] Wang, L., Liu, K.H. (2007). Implementation of a webbased real-time monitoring and control system for a hybrid wind-PV-battery renewable energy system. In International Conference on Intelligent Systems Applications to Power Systems (ISAP 2007), 5-8 November 2007. IEEE, 1-6.

[10] Guozhen, H., Tao, C., Changsong, C., Shanxu, D. (2009). Solutions for SCADA system communication reliability in photovoltaic power plants. In 6th International Power Electronics and Motion Control Conference (IPEMC '09), 17-20 May 2009. IEEE, 2482-2485.

[11] Macken, K.J.P., Vanthournout, K., Van den Keybus, J., Deconinck, G., Belmans, R.J.M. (2004). Distributed control of renewable generation units with integrated active filter. IEEE Transactions on Power Electronics, 19 (5), 1353-1360.

[12] Dharmawan, H.A., Ali Sam, A.M. (2012). A compact remote monitoring system for a three-phase $10-\mathrm{kVA}$ energy-efficient switchable distribution transformer. IEEE Transactions on Instrumentation and Measurement, 61 (3), 618-628.

[13] Gagliarducci, M., Lampasi, D.A., Podesta, L. (2007). GSM-based monitoring and control of photovoltaic power generation. Measurement, 40 (3), 314-321.

[14] Perumal, T., Ramli, A.R., Leong, C.Y. (2008). Design and implementation of SOAP-based residential management for smart home systems. IEEE Transactions Consumer Electronics, 54 (2), 453-459.

[15] Vairamani, K., Venkatesh, K.A., Mathivanan, N. (2011). Design and development of ZigBee based instantaneous flat-plate collector efficiency measurement system. Measurement Science Review, 11 (2), 57-60.

[16] Sharp Electronics Corporation. (2008). Sharp NE170U1 multipurpose module. http://files.sharpusa.com /Downloads/Solar/Products/sol_dow_NE170U1.pdf

[17] Colak, I., Bayindir, R., Kabalci, E. (2009). Modeling of a three phase SPWM multilevel VSI with low THD using Matlab/Simulink. In 13th European Conference on Power Electronics and Applications (EPE '09), 810 September 2009. IEEE, 1-10.

[18] Colak, I., Kabalci, E., Bayindir, R., Sagiroglu, S. (2009). The design and analysis of a 5-level cascaded voltage source inverter with low THD. In International Conference on Power Engineering, Energy and Electrical Drives (PowerEng '09), 18-20 March 2009. IEEE, 575-580.

[19] Glover, I., Grant, P. (2000). Digital Communications (2nd edition). Prentice Hall.

[20] Couch, L.W. (1997). Digital and Analog Communication Systems (5th edition). Prentice Hall.

Received January 23, 2013. Accepted October 11, 2013. 